\title{
SYSTEMATIC CHARACTERIZATION OF COMPONENT FAILURES FOR THE DIII-D TOKAMAK
}

\author{
by \\ P.I. PETERSEN
}

This is a preprint of a paper to be presented at the 5th International Symposium on Fusion Nuclear Technology, September 19-24, 1999, in Roma, Italy, and to be published in Fusion Engineering and Design.

\author{
Work supported by \\ the U.S. Department of Energy \\ under Contract No. DE-AC03-99ER54463
}

PROCESSED FROM BEST AVALLABLE COPY

GA PROJECT 30033

AUGUST 1999 


\section{DISCLAIMER}

This report was prepared as an account of work sponsored by an agency of the United States Government. Neither the United States Government nor any agency thereof, nor any of their employees, make any warranty, express or implied, or assumes any legal liability or responsibility for the accuracy, completeness, or usefulness of any information, apparatus, product, or process disclosed, or represents that its use would not infringe privately owned rights. Reference herein to any specific commercial product, process, or service by trade name, trademark, manufacturer, or otherwise does not necessarily constitute or imply its endorsement, recommendation, or favoring by the United States Government or any agency thereof. The views and opinions of authors expressed herein do not necessarily state or reflect those of the United States Government or any agency thereof. 


\section{DISCLAIMER}

Portions of this document may be illegible in electronic image products. Images are produced from the best available original document. 


\section{ABSTRACT}

A fusion reactor will be a fairly complex system consisting of many components. All the components are required to work in order to produce a plasma and control it. Some of the components will be large, and for economic reasons there will not be spares for all components. It is therefore important to have a system whereby troubles are communicated, recorded and analyzed. Such a trouble report system has been in place at the DIII-D tokamak facility for many years. The purpose of the system is to easily facilitate communication between the people that discover problems and those that fix the problems. The trouble sheets are logged into a computer database that is used to characterize the kind of problems that the facility experiences, and determine which equipment, software, or human errors are causing significant downtime. The information is also used to evaluate whether sufficient maintenance is done to the equipment and to provide a basis for replacing it. The original system was based on paper forms. About a year ago the system was changed to a web-based system. In the new system a trouble report is filled out using a web browser, and the information is emailed to the repair personnel and managers as soon as the form is submitted through the web. The paper will discuss the problems experienced at the DIII-D facility, and how the information is used to adjust the preventive maintenance schedule. 


\section{INTRODUCTION}

In 1987, just after the Doublet III tokamak was modified to the DIII-D tokamak a trouble reporting system was instituted at the DII-D facility. The main purpose of the system was to ensure that troubles were taken care of and got documented. The system was based on a paper form, which was divided into three sections. The person who was reporting the trouble filled out the first section. The personnel doing the repair or their supervisor filled out the second section after the repair was completed. The third section was filled out by the DIII-D facility coordinator and indicated his approval of the work. After the three sections were filled out, the data on the form was entered into a simple database.

In 1998 the system was changed to a web based system. In the new system, the division of the form into three sections is kept, but the form is now only available on the web and the different people fill it out from any computer terminal. There are several advantages to a trouble report system and several more have been added by making the system web-based.

Since 1987, when the trouble report system was established, through mid-April 1999 the DIII-D tokamak was scheduled to operate 8832 hours, but was actually only operated 6532 hours. During this time 3814 trouble reports have been filed, of these 2272 resulted in downtime of the tokamak (downtime is defined in the section on DIII-D operations). This gives an availability of $74 \%$, and means that there has been a problem of one type or another about every 2 hours on average, and that every 3 hours on average a problem caused downtime. It is important to realize that a research device is often operated very differently than a commercial plant might be operated. In an experimental program, we often change and upgrade components and operating parameters. As a result a certain non-zero level of downtime is expected and accepted in return for the flexibility to run a wider range of experiments. In a commercial plant more attention will be paid to conservative design and redundancy for critical components.

There are several benefits to having a trouble report system. The main reason for establishing a trouble report system at DIII-D is to ensure that problems get fixed efficiently and that they get 
documented. The system helps establish better communication between the person discovering the problem and the people that have to fix it. Misunderstandings of what has to be done are reduced, and the personnel doing the repairs have a record of what happened.

The trouble reports are reviewed several times during a year to find trends in the troubles and to find out in what areas refurbishment can be done most cost efficiently. From the trouble report system it is also possible to find the frequency of failure of the different components, which is of interest for people making risk analysis and availability studies for future fusion devices.

The paper is organized as follows. The DIII-D facility and the components that make up the facility are described in the Section 2 together with how the DIII-D tokamak is operated, and the definition of availability and downtime. The DIII-D web-based trouble report system is described in Section 3. The troubles that are encountered in the DIII-D facility are reported in Section 4. The specific troubles with the toroidal power supply are detailed in Section 5, and some other components are covered in Section 6. The conclusion of the paper is given in Section 7. 


\section{THE DIII-D FACILITY}

A large number of systems is required to operate the tokamak. Several electrical substations are located on site to provide the power that is needed to operate the tokamak and auxiliary heating power systems. About 60 power supplies are used to power all the coil systems. Approximately 50 vacuum pumps are used for the tokamak, neutral beam, and diagnostic vacuum systems. There are 60 different diagnostic systems on the DIII-D tokamak. The instrumentation and control systems are fairly extensive and includes systems to collect data required for operating the tokamak as well as for diagnosing the plasma. There are three different auxiliary heating systems on the DIII-D tokamak. The 20 MW neutral beam system consists of four neutral beam lines each with two beams. Each beam can deliver $2.5 \mathrm{MW}$ of power to the plasma. The $6 \mathrm{MW}$ fast wave system, which is used to heat the ions, consists of three radio frequency transmitters. Three $2 \mathrm{MW}$ transmitters operate in the frequency range $60-120 \mathrm{MHz}$ and each delivers about $1 \mathrm{MW}$ of power to the plasma. The Electron Cyclotron Heating system consists of three $1 \mathrm{MW}$ gyrotrons. The system is currently being expanded by adding three more $1 \mathrm{MW}$ gyrotrons. A large number of computers and an extensive computer networks are required to operate the tokamak and the auxiliary heating systems, and to acquire, store, and analyze the data that is need for operating the device and diagnosing the plasma.

The operation of the DIII-D tokamak is divided into several categories; plasma physics operations, power supply testing, and maintenance, just to mention a few. The main purpose of operating the tokamak is to do plasma physics experiments, and this is normally done in periods of three weeks followed by two to three weeks of maintenance, modifications and data analysis. The funding available and the fact that many of the same personnel are required to operate and maintain the tokamak dictate this division. The DIII-D tokamak has been operated between 13 to 24 weeks per calendar year. The normal operating day is from 8:30 a.m. to 5:00 p.m. on weekdays. The operation is preceded by about 2 hours of preparation time and followed by about an hour to shut down the equipment for the night. 
The availability is defined as the actual operation time divided by the scheduled operation time. A tokamak shot is fired about every 12 to 15 minutes, when it is operating. If the research team is ready and a shot is not fired within 15 minutes of the previous shot, a trouble report must be filed and 15 minutes of downtime will be charged to the cause for the delay. The causes for downtime are divided into three groups: Hardware failure, software, or human errors. Trouble reports are also filled out at times for troubles that do not cause downtime. 


\section{THE DIII-D WEB-BASE TROUBLE REPORT SYSTEM}

The form that has to be filled out to report a trouble is shown in Fig. 1. In the trouble report system, it is important to correctly identify the components that caused a problem and the person that is responsible for the repair. The identification of the components is done by first choosing the group that the component belongs to. After the group has been chosen, the corresponding subgroup become available on the form and can be chosen. Similarly, when the subgroup has been chosen, the component can be chosen. If the reporter does not know the group or subgroup that an item is listed under, they can then choose the link to "Help find an item." This link presents the reporter with an input box, wherein they can write part of or all of the name of the component. The form will then present the reporter with a list of possible options from which they can choose. When an item is chosen from the list, the program will automatically fill in the group, subgroup, and component input boxes on the input form.

As soon as the subgroup has been chosen on the input form, the program will fill in the task leader and email input boxes. The reporter has only to fill out the description of the problem and identify themself. Pressing the "submit" button causes the data to be transferred to the trouble report database and an email to be sent to the task leader in charge of the repair. After the repair has been done, the task leader fills out the next section of the form, which is shown in Fig. 2. The last section, which indicates an approval of the repair is signed off by the DIII-D facility coordinator.

In addition to the form, some statistical analysis of the trouble reports is available on the web and can be used to identify trouble areas that require extra attention. Most of the database management, for example addition of subgroups or components, changes of area of responsibility, etc., is also done on the web to allow more than one person to manage the system.

There are several benefits to a web-based trouble reports system compared to one based on paper forms; 1) The manager and the people responsible for the repair as well as the facility coordinator are automatically notified. 2) It is much easier to file a trouble report, since 


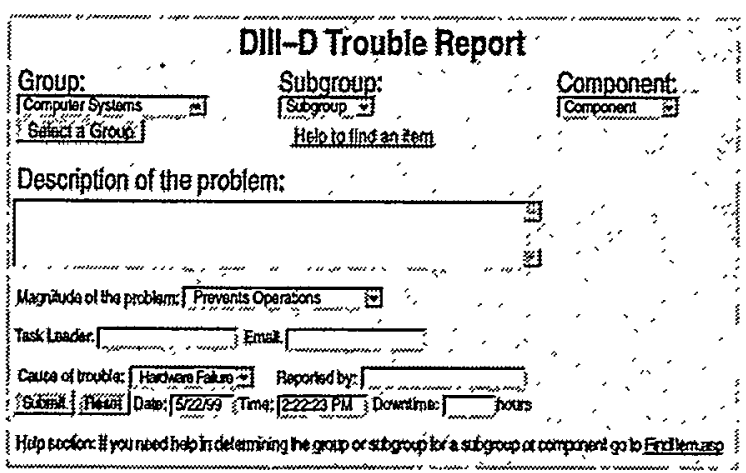

Fig. 1. DIII-D trouble report input form.

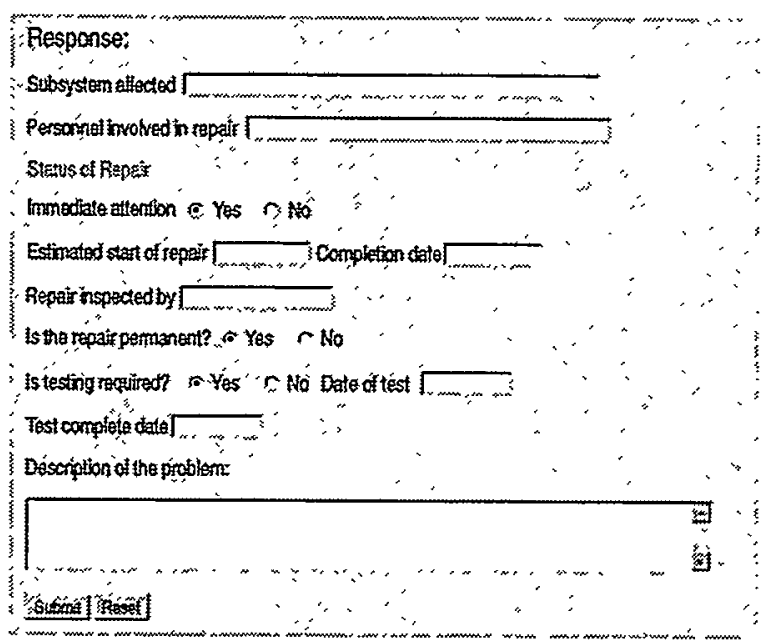

Fig. 2. Response section of the trouble report form.

computers are available essentially everywhere on site. 3) The reporter directly enters the data into the database. This eliminates the clerical person who in the paper-based system had to transfer the data from the forms to the database. 4) In the paper-based system, different reporters would use different names for the same component and attempts to standardize the names met only limited success. In the web-based system, the reporter is force to select the component from a unique list, thus avoiding ambiguities about naming the component. The reporter aided by the computer database selects the group and subgroup for the component at the time he fills out the form. 5) Paper forms were at times lost. With the web system, there is nothing to misplace. 6) In the web-based system the statistical analysis of the trouble reports is easily available to a broad audience. 


\section{TROUBLES}

The availability for the DIII-D tokamak has been fairly constant over the years as shown in Fig. 3, except for 1997, when we experienced a control system problem with our power conditioning units (HX choppers), which took longer than normal to resolve. The average time between troubles and the average downtime for a trouble as function of time is shown in Fig. 4 . The mean time between troubles and the average downtime for trouble have decreased over the years. There are several reasons for this. The DIII-D facility has been under constant development and new hardware has constantly been added to the facility increasing its complexity. In addition, as the physics experiment have become more sophisticated, they have become more dependent on a larger number of subsystems and diagnostics operating simultaneously. Thus a single subsystem or diagnostic failure may result in a delay in the experiment and downtime. Thus as the facility matured there were more reasons to stop the operations and fix a problem. On the other hand, causes of long periods of downtime have generally been addressed and eliminated. Figure 4 also shows that the average downtime for a trouble has dropped over the years. The reason is that more trouble reports with no associated downtime are being written, and the downtime for those reports that have downtime has decreased over the years. This occurs because the people making the repairs know the systems better and can thus make the repairs faster.

With an average availability of $74 \%$ a lot of extra operating time could be made available if the number of troubles and the downtime for each trouble could be reduced. We are trying to reduce the downtime. However, the tokamak is a research machine, where new experiments are cornerstones in making progress. This often implies that the tokamak is operated close to its design limits and with unproven components and subsystems. Thus a compromise has to be made between making the operating space as large as reasonable versus availability of the device. 


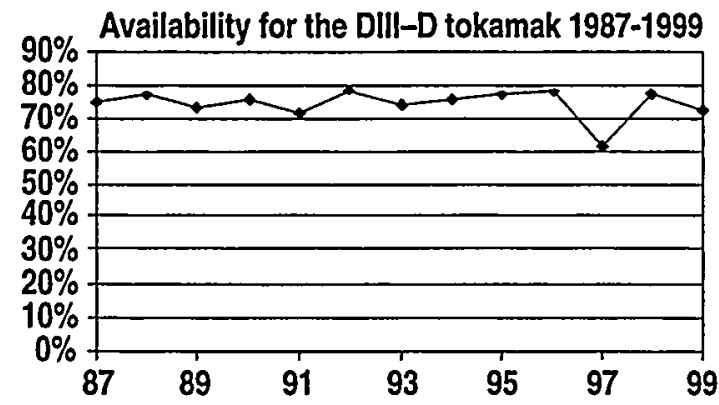

Fig. 3. Annual availability for DIII-D tokamak.
Downtime Per Trouble and Average Time Between Trouble

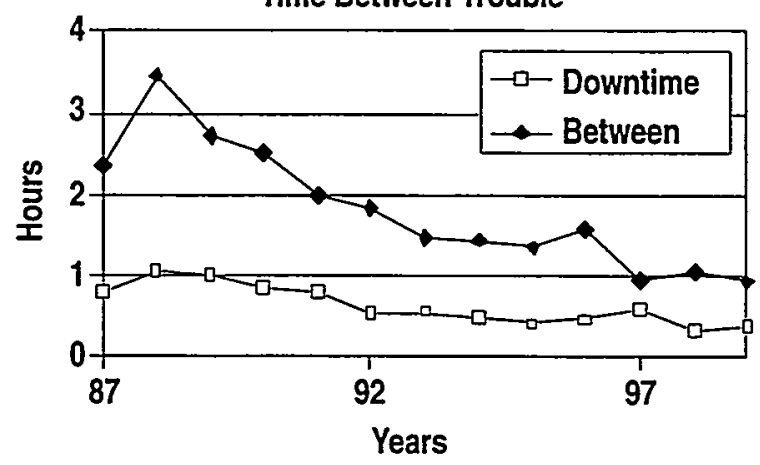

Fig. 4. Downtime per trouble and average time between troubles.

The major downtime of the DIII-D tokamak is attributed to the power systems group (see Table 1). This is owing to the more than 60 d.c. supplies, current regulators, and high voltage power systems along with their associated prime power systems needed to run the tokamak. The next group is the tokamak operations group, which is responsible for the coils, many of the operations interlocks and the gas puff system. Third is the vacuum and fluid groups, which are responsible for the plasma chamber, neutral beam and diagnostics vacuums. Fourth is the computer group, which is responsible for all the computers that are located on site.

In Table 2 are shown the average time between troubles and the total downtime for subgroups in the period 1987-1999. The subgroups are from all the groups not just power systems, even though the subgroups from this group dominate. The subgroups covers individual systems, which can be a single power system such as the large toroidal power supply, or a group of power switching units or pumps, where the units are smaller. When we look at the average time between troubles for the subgroups (Table 2) we find that the toroidal power supply (B power supply) most frequently has problems and accounts for the most downtime. This is the largest power supply and it is usually run very close to its operating limits. The next most frequent cause for downtime is the X-choppers, which, together with the HX-choppers, are switching power-conditioning units used to power the field-shaping coils. The X-choppers are 
Table 1

Number of trouble reports and downtime by groups (1987-1999)

\begin{tabular}{lcc}
\hline \multicolumn{1}{c}{ Group } & Total No. & Downtime \\
\hline Power Systems & 1217 & 841 \\
Tokamak Operations & 635 & 606 \\
Vacuum and Fluids & 390 & 299 \\
Computer Systems & 436 & 171 \\
Physics & 259 & 109 \\
I\&C & 282 & 102 \\
Diagnostics & 172 & 74 \\
Neutral Beams & 169 & 54 \\
DIII-D Coordination & 36 & 38 \\
Safety & 94 & 19 \\
HV Power Supplies & 44 & 18 \\
ECH & 33 & 17 \\
ICH & 14 & 14 \\
DIII-D Facility & 28 & 8 \\
Other & 18 & 6 \\
Mechanical Engineering & 5 & 3 \\
\hline
\end{tabular}

Table 2

Average time between troubles and total downtime for some subgroups

\begin{tabular}{lccc}
\hline \multicolumn{1}{c}{ Subgroup } & $\begin{array}{c}\text { Total } \\
\text { No. }\end{array}$ & $\begin{array}{c}\text { Downtime } \\
\text { (Hours) }\end{array}$ & $\begin{array}{c}\text { Av. Time } \\
\text { between Tr } \\
\text { (Hours) }\end{array}$ \\
\hline B Power Supply & 205 & 165 & 32 \\
X Choppers & 161 & 64 & 41 \\
PCS & 160 & 67 & 41 \\
HX Choppers & 153 & 89 & 43 \\
Data Acquisition & 151 & 53 & 43 \\
E Power Supply & 150 & 77 & 43 \\
\hline
\end{tabular}


older than the HX-choppers and there are a large number of both (20 X-chopper $600 \mathrm{~V}$ units, and 16 HX-chopper $1200 \mathrm{~V}$ units).

The third most frequent cause for downtime is the plasma control system, which is a digital control system that we started using in 1993. This system, which allows us to do experiments that would be very difficult to impossible to do with an analog controls system, is constantly being modified to support the current experiments. This is a clear example of where we allow a system to cause more downtime than would be allowed in a fusion power plant in order to try out new ideas in a timely manner. The E power supply (the ohmic heating power supply) is a power supply at about the same size as the toroidal power supply, however, it is only used at a fraction of its full capacity, and thus it causes less downtime and fewer trouble reports.

In all, 169 subgroups are included in the trouble report system. However, only a few (the ones with the most frequent troubles) are included in the Table 2. The number of subgroups keeps increasing as new equipment is brought online. The latest, three new power supplies for control of resistive wall modes, have been added and soon additional gyrotrons will be added to the list of subgroups. 


\section{THE TOROIDAL POWER SUPPLY}

The toroidal power supply is the subgroup that causes the most downtime. This power supply is the largest power supply and is often operated near its design limits. A historical plot of the downtime for the toroidal power supply is shown in Fig. 5. In 1989 and 1991 the downtime for the supply was high and the power supply was retrofitted with additional SCRs to reduce the frequent failure of SCRs.

The problem areas for the toroidal power supply are broken down in four groups "other" (38\%), SCRs (33\%), breakers (19\%), and gate drive boards (10\%). The average time between failures in the toroidal power supply is 54 hours for the group "other", 62 hours for SCRs, 110 hours for breakers, and 225 hour for the gate drive boards. Since there are 960 SCRs in the toroidal power supply the failure rate for a given SCR is $1.7 \times 10^{-5}$ hour-1. From the data there is no indication that the SCR failure rate is increasing with age.

The are 48 gate drive boards, thus the failure rate of each is $9.2 \times 10^{-5}$ hour $^{-1}$. There are 4 breakers for the toroidal supply, thus the failure rate is $2.3 \times 10^{-3}$ hour ${ }^{-1}$. This is a high failure rate for breakers and is mainly due to the fact that the breakers are opened fairly often; whereas they were designed for intermittent use. Every time someone needs access to the machine hall between shots the breakers are opened.

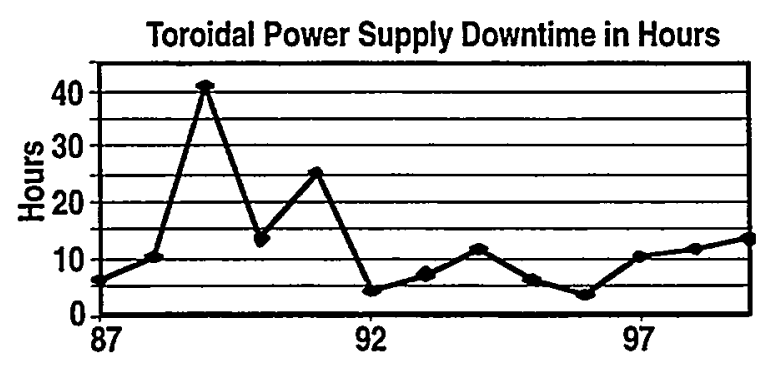

Fig. 5. Downtime for toroidal power supply. 


\section{OTHER COMPONENTS}

The number of vacuum leaks that have developed in the vessel and caused machine downtime is 24 . Thus the vacuum failure rate for the DIII-D vessel during operations is $3.6 \times 10^{-3}$ hour-1.

There are three large $5000 \mathrm{l} / \mathrm{s}$ turbo-molecular pumps on the DII-D tokamak pumping on the vacuum chamber. The vibration spectrum is routinely measured on these pumps and when it gets abnormal the pump is removed for servicing and replaced with another pump. However, the pumps have automatically been shutdown 23 times due to a number of different problems of which the most prevailing ones have been: problems with the pump water cooling system and controller. The failure rate of a given pump for these kinds of problems is $2.2 \times 10^{-4} \mathrm{hour}^{-1}$. In this case the total hours $(\sim 300)$ that have elapsed since the first pump was installed has been used instead of the operating hours, used for the other equipment, which is only operational during tokamak operation. 


\section{CONCLUSION}

A trouble report system implemented on the DIII-D tokamak helps keep track of problems and allows problems to be analyzed to determine where refurbishment is most cost efficient. The web-based system makes it easier for personnel to report and respond to troubles. The average time between troubles has decreased due to the increased complexity of the facility over the years. The average downtime for troubles has also decreased, since the personnel know the systems better and thus can do the repairs faster. In addition, the causes of long periods of downtime have generally been addressed and eliminated. Thus the availability of the facility has been kept fairly constant at $74 \%$. The power systems group is charged with most downtime due to the large number of large power supply systems. The main cause of downtime at DIII-D is due to the toroidal power supply, which is the largest and most stressed power supply. Even reliable components, such as silicon controlled rectifiers, are cause of a major part of the downtime, since there are so many of them. The data from the DIII-D trouble report system are made available to other institutions that study failure rate and reliability of fusion plants. However, it should be recognized that as a physics research facility DIII-D is continuously exploring new operating regimes and facility configurations atypical of future power plants. 


\section{ACKNOWLEDGMENTS}

Work supported by U.S. Department of Energy under Contract No. DE-AC03-99ER54463. 